$\underline{\mathbf{P}-1}$

\title{
Cytotoxicity and Antioxidant Activity of a Steroidal Saponin Isolated from Dracaena Umbratica
}

\author{
Raudhatul Jannah M.Z1 ${ }^{1}$, Zurina $\mathrm{M}^{2}$, Zaini $\mathrm{Y}^{3}$, Shaida Fariza $\mathrm{S}^{4}$, Lia Dewi Juliawaty ${ }^{5}$ and Nordin $\mathrm{L}^{6}$ \\ ${ }^{1}$ Faculty of Applied Science, Universiti Teknologi MARA, 40450 Shah Alam, Selangor, Malaysia; ${ }^{1,2,3}$ Faculty of Applied \\ Science, Universiti Teknologi MARA Perlis,02600 Arau, Perlis, Malaysia; ${ }^{4}$ School of Biology, Universiti Sains \\ Malaysia, 11800, Gelugor, Pulau Pinang, Malaysia; ${ }^{5}$ Institut Teknologi Bandung, Jln Ganesha 10, 40132, Bandung, \\ Jawa Barat, Indonesia; ${ }^{6}$ Institute of Bioscience, Universiti Putra Malaysia, 43400, Serdang, Selangor, Malaysia
}

Dracaena umbratica is a medicinal plant which belongs to Dracaenaceae family. It is found plentifully in Malaysia peninsular. This shrub is locally known as Senjuang. The decoction of the roots was reported as Malaysian folk medicine for treating rheumatism ${ }^{1}$. As the result of our research on Dracaena umbratica, a spirostenol type of steroidal saponin was successfully isolated from methanol extract of the leaves of this shrub via normal phase vacuum liquid chromatography eluted with methanol. Its structure was confirmed by spectroscopic analysis as $3-O-[\alpha-\mathrm{L}$-rhamnopyranosyl $(1 \rightarrow 4)-\alpha$-L-rhamnopyranosyl $(1 \rightarrow 4)-\beta$-Dglucopyranosyl]-25(R)-spirost-5-en-3 $\beta$-ol. This compound was then tested for cytotoxicity against murine leukimia cell line P-388 followed by antioxidant activity against lipid peroxidation using FTC (Ferric thiocyanate) and TBA (Thiobarbituric acid) assays ${ }^{2}$. The cytotoxicity test against murine leukemia cell line P-388 was conducted using MTT (Microculture tetrazolium) assay ${ }^{3}$. The $\mathrm{IC}_{50}$ value calculated was $3.5 \mathrm{ppm}$ which indicated positive activity. ( $\mathrm{IC}_{50}<4 \mathrm{ppm}$ for pure compound is considered active- (US NCI). Besides, this compound showed moderate antioxidant activity. The percentage of inhibition based on FTC assay was $71.9 \%$ whereas for TBA was $71.0 \%$ as compared to $97.0 \%$ inhibition of BHT (Butylated hydroxytoluene) which was used as the standard. Based on these results, it can be concluded that this compound showed cytotoxicity activity against murine leukemia cell line P-388 as well as antioxidant activity against lipid peroxidation. 